\title{
0 igualitarismo de um liberal: com e para além de Tocqueville ${ }^{1}$
}

\author{
Renato Moraes* \\ João Alexandre Peschanski**
}

\section{Resumo}

0 presente trabalho percorre as observações tocquevilleanas quanto ao sentido histórico da formação da nação norte-americana para reconstruir o princípio norteador de sua análise: a possibilidade fática da coexistência de princípios de igualdade e de liberdade. Mais especificamente, analisa o caminho inexorável das nações modernas em assegurar a liberdade na igualdade, de acordo com Tocqueville. A relação interna da díade de valores aqui exposta enseja a construção de um tipo especificamente moderno, um conceito específico de democracia que, mais que uma simples forma de governo, constitui um tipo específico de sociedade, na qual ganha centralidade o papel assumido pelo "patriotismo municipal" das comunas e pela "liberdade política local" na construção de uma disposição dos indivíduos a tomarem para si a resolução conjunta de seus problemas coletivos. Com isso, o artigo pretende mostrar como, em Tocqueville, a noção de autogoverno representa a forma mesma da estruturação da liberdade fundada na igualdade cívica entre sujeitos autônomos.

\section{Palavras-chave}

Teoria política. Tocqueville. Autogoverno

\begin{abstract}
This article goes through Tocquevillean ideas on the historical formation of the American nation in order to identify a guiding analytical principle: the actual possibility of the principles of equality and freedom to coexist. More specifically, it analyzes the inevitable path of modern nations in order to ensure freedom in equality, according to Tocqueville. The internal relationship between these two values leads to establishing a specific modern type, a specific
\end{abstract}

\footnotetext{
1 Agradecemos aos pareceristas anônimos os comentários e sugestões críticas que, além de pertinentes, contribuíram para aprofundar ainda mais o argumento aqui desenvolvido.

* Professor-adjunto de Ciência Política da Universidade Federal de São Carlos; Doutor em Ciência Política pela Universidade de São Paulo. E-mail: rmoraes@ufscar.br .

** Doutorando em Sociologia pela University of Wisconsin-Madison. joalpe@gmail.com .
} 
concept of democracy, that more than a simple form of government constitutes a specific type of society, in which "municipal patriotism" of the communes and "local-political freedom" are central to building individual dispositions toward collectively solving their issues. With that, this article intends to show how, in Tocqueville, the notion of self-government represents the actual form of structuring freedom in civic equality among autonomous subjects.

\section{Keywords}

Political theory. Tocqueville. Self-government.

\section{Introdução}

Este trabalho se propõe a entender o papel das estruturas sociais na obra de Alexis de Tocqueville sobre a democracia na América. O objeto é de certo modo não tocquevilleano, pelo menos no que comumente é enfatizado como característico dessa vertente de pensamento: em sua etnografia política dos Estados Unidos no início do século XIX, Tocqueville enfatiza a ideia de que a sociedade que observa se sustenta não por uma administração ou um governo, mas por sentimentos partilhados, valores arraigados e propagados, voluntarismo e participação (JASMIN, 2002). Goldberg (2001) identifica duas formas dominantes de interpretação da obra tocquevilleana. A primeira, que nomeia "sistematizadora", considera que a teoria democrática de Tocqueville já atingiu seu objetivo, a saber, identificar as condições com que a liberdade democrática pode se consolidar. Na nossa perspectiva, essa forma de interpretação é insuficiente na medida em que considera o pensamento tocquevilleano sobre a história como "morta", isto é, sem capacidade explicativa das dinâmicas subsequentes, sendo incongruente com uma leitura tocquevilleana que se limita a entender teoricamente um processo histórico definido. A segunda, chamada "historicista", esvazia ainda mais a capacidade explicativa de Tocqueville, argumentando que seu pensamento está diretamente vinculado ao contexto que observa, não podendo, finalmente, ser considerado uma teoria histórica. Distanciamo-nos dessas duas formas de interpretação e, seguindo Goldberg (2001, p.303), propomos uma reconstrução da teoria tocquevilleana, que

pressupõe que uma teoria tem de ser resgatada e reconstruída em uma nova forma exatamente porque, em algum aspecto, não atingiu seu objetivo, $[\ldots]$ em vez de simplesmente suprimir ambiguidades e 
inconsistências não resolvidas, a reconstrução teórica reformula a teoria de modo a ser mais congruente.

A ideia de que a democracia nos Estados Unidos se fundamenta em valores partilhados se identifica com os preceitos do liberalismo; o enfoque proposto aqui apresenta uma leitura republicana da concepção tocquevilleana da democracia norte-americana.

Neste artigo, propõe-se um triplo exercício no sentido de uma "reformulação congruente" do pensamento de Tocqueville. Em primeiro, identifica-se o mecanismo de explicação da história, de tal modo a explicitar as dinâmicas de encadeamento de evento que o autor desenvolve, o que se perde ao adotar uma estratégia de leitura fundamentada na recuperação do contexto em que as ideias são formuladas. A reformulação é, nesse sentido, a compreensão dos mecanismos abstratos da trajetória histórica, em que a própria história é objeto de análise, a partir de uma interpretação daquilo que veio e da direção à qual se vai. Em segundo, interpreta-se o fundamento da moral no pensamento tocquevilleano, identificando as bases materiais da filosofia e da religião. A proposta aqui é entender a dinâmica em nível elevado de abstração entre vida filosófica, pensamento religioso e Estado. Por fim, busca-se desenvolver a teoria do individualismo própria a Tocqueville, indicando a confluência positiva entre particularismo e povo. Esses três elementos que aqui interpretamos sugerem que consigamos destilar da reflexão tocquevilleana mecanismos analíticos que, independentemente do contexto histórico e de uma finalidade dada a priori, sirvam para estabelecer as bases relativamente estruturantes de sua conceituação da política.

Nesse sentido, entende-se que, no próprio Tocqueville, a existência de governos democráticos está associada a uma estrutura republicana prévia. Integram essa estrutura instituições e um tipo específico de cultura cívica ${ }^{2}$ - que denominamos aqui republicana -, em interação dinâmica, dos quais

\footnotetext{
${ }^{2}$ É importante salientar que a noção de cultura cívica, assim como seu significado, ainda não havia sido formatada no período em que Tocqueville escreve. O modo como usamos a expressão aqui refere-se principalmente a dois processos interconectados: o consentimento de uma autoridade organizada coletivamente, como o Estado, e a participação ativa na condução associativa e política da coletividade. O argumento tal qual o construímos se propõe a entender as bases materiais desses processos, sendo que interpretações correntes da obra tocquevilleana puseram principalmente o foco em aspectos conjunturais e circunstanciais e em questões ideárias.
} 
emana a própria possibilidade da ação política. De certo modo, seguimos parte da trajetória analítica de Skocpol (1997), para quem a vitalidade cívica norte-americana que Tocqueville observou estava diretamente vinculada a instituições em processo de consolidação e nacionalização; distanciamo-nos dessa autora, entretanto, na medida em que ela constrói o argumento do vínculo entre vitalidade cívica e instituições como uma suposta contraposição ao pensamento tocquevilleano e, para nós, há elementos republicanos basilares na própria obra tocquevilleana, incluindo aí a concepção de tradição religiosa e de democracia.

Propomos aqui uma incursão teórico-analítica no pensamento tocquevilleano, não uma volta historiográfica à América do século XIX. Os elementos igualitários, mostramos, estão presentes na própria etnografia política de Tocqueville. A obra tocquevilleana, em especial A democracia na América, vale notar, é marcada por ambiguidade, pelo conflito entre a tradição do Antigo Regime e a convicção na existência de um sentido de justiça, influenciada pelas Sagradas Escrituras. A revelação dessa ambiguidade e desse conflito permeia a análise que segue, que pensa com e para além de Tocqueville.

\section{Teorização e observação da história}

Tocqueville não apresenta apenas observações históricas, a esmo, mas adota uma estratégia sui generis de teorização histórica. Destacam-se dois aspectos nessa estratégia: a criação do enredo histórico no modo da tragédia e a fundamentação explicativa em leis do desenvolvimento histórico de tipo mecanicista (WHITE, 1994). A combinação desses aspectos é, à primeira vista, esdrúxula: ao mesmo tempo literária e cientificista, fatalista e dedutiva; no entanto, expõe um posicionamento próprio de Tocqueville em relação ao mundo que observa - no geral oculto, já que este não tratou de fato de teoria da história, e, às vezes, com enunciação contraditória, em especial nos escritos mais propriamente de polêmica.

O estilo tocquevilleano é marcado pelo irônico e pelo trágico, mas o enredo mantém um fio ontológico trágico. Os traços irônicos remontam à experiência pessoal do autor, especialmente sua inserção ativa na vida política de seu tempo, ou seja, carrega o viés do polemista. A passagem da ironia para a tragédia, segundo Cohn (2000a), coloca-se necessariamente em um plano de disputa, até pela própria experiência de Tocqueville, dividido entre o universo aristocrata, seu lócus originário, e a realidade democrática, 
que observa e identifica como substancialmente determinado vir-a-ser. É trágico o enredo desse vir-a-ser, o movimento político de passagem para a democracia, que se apresenta quando, não satisfeito em perceber as mudanças ocorridas em seu tempo, busca caracterizá-las tanto em sua natureza peculiar quanto naquilo que as anima. Esse enredo o leva a considerar a ruptura do equilíbrio, o que a seguir denominamos transação de histórias, que no sentido mais radical desemboca na transição mais radical, a Revolução. "Mas não se mostra suficientemente claro a respeito de se a democracia é uma exigência da fraqueza resultante do individualismo ou se o individualismo é uma consequência inevitável da democratização”. (SANTOS, 2004, p.98).

A transação da história diz respeito ao tipo de teoria de ruptura histórica que Tocqueville desenvolve. Para ele, processos aparentemente desconexos estabelecem vínculos que fazem com que coevoluam. Assim, aquilo que parecia independente estabelece uma dependência que instaura uma relativa afinidade entre processos sociais. $\mathrm{O}$ desmantelamento da aristocracia, que ocorre por sua dinâmica própria, em perversões instauradas e reproduzidas no seio dessa própria configuração, cria um vínculo com outro processo, a constituição democrática, transacionando os incentivos próprios de cada dinâmica, a tal ponto que, quando afinados, já não se pode dissociá-los e, como peças de um mesmo sistema, agem um sobre o outro, criando assim um mecanismo histórico definido e relativamente robusto.

A perspectiva mecanicista do processo histórico se faz marcar por uma noção de que antagonismos políticos, quando ocorrem, estão determinados a encontrar uma e apenas uma solução histórica. Isso não quer dizer que embates conjunturais estão determinados, mas que, na perspectiva mais geral, no agregado, o conjunto histórico desses embates tem um devir determinado. Essa perspectiva enfatiza, portanto, a compreensão da finalidade do antagonismo e isso se expressa, no texto tocquevilleano, pela contraposição de categorias, por exemplo, entre igualdade e liberdade, privado e público, burguês e cidadão, interesses e vícios. Essas díades são empregadas no sentido de apontar para um movimento ascendente da história humana, rechaçando uma percepção circular. Vale notar que o mecanicismo de Tocqueville se caracteriza por um teor fraco, ou seja, é provável que a lei da determinação histórica opere em cada momento histórico, mas não é sempre necessário, por mais que, como dito, no agregado, haja uma tendência ascendente. Esse ponto é importante, pois mantém a centralidade de condução nos esforços continuados e na ação política humanos (VIANNA, 1997, p.94). Também cabe ao sujeito apaziguar as lutas entre os contrários, de tal sorte a produzir 
alguma forma de harmonização.

O objeto de A democracia na América é, para além da estratégia sui generis de exposição histórica de Tocqueville, peculiar. Não se trata do excepcionalismo norte-americano apenas, entendido como um agregado de particularismos. ${ }^{3}$ O objeto tocquevilleano é fundamentalmente a comparação entre o que ele vê e o que ele viu, entre a sociedade de alhures e a sua natal. O componente comparativo, às vezes latente, outras manifesto, é o núcleo da etnografia política a que se dispõe Tocqueville - tratou-se de um esforço em olhar "para além da França para melhor ver a França", nas palavras de Cohn (2000a, p.31). Nesse sentido, a análise do surgimento da democracia nos Estados Unidos, resultado monumental da obra tocquevilleana, é, de certo modo, consequência indireta de seu esforço comparativo. A comparação se fundamentou essencialmente na identificação de disparidades, singularidades, não comunalidades, possivelmente existentes.

Tocqueville não se limitou a descrever uma experiência histórica, temporalmente estabelecida e espacialmente determinada, nem a comparar características visíveis de duas sociedades díspares, mas enquadrou suas observações em uma preocupação orientada por um princípio norteador, em um nível mais elevado de abstração, a possibilidade fática de conciliar igualdade e liberdade ou, nos termos de Gahyva (2012, p.172), "a questãochave para a qual se orientavam suas preocupações versava sobre a possibilidade de reatualização dessa qualidade aristocrática - a liberdade - em um contexto igualitário”. Em verdade, na obra tocquevilleana, trata-se não de uma possibilidade, mas de um destino inexorável: cabe às nações modernas assegurar a liberdade na igualdade. Para justificar essa colocação, Tocqueville estabelece parâmetros que possibilitem a coexistência harmoniosa entre as liberdades e um processo de desenvolvimento igualitário, de maneira coerente.

Apresenta-se, assim, um primeiro grande drama tocquevilleano: preservar a liberdade na igualdade. Em sua perspectiva, a democracia somente

\footnotetext{
${ }^{3}$ Nesse aspecto, distanciamo-nos das vertentes culturalista e idealista de análise da formação norte-americana, que buscam identificar qualidades particulares da vida social nos Estados Unidos, dando-lhes fundamentação explicativa para desdobramentos institucionais e cívicos próprios, como o tipo singular de relação capital-trabalho ou o modelo de Estado de bem-estar social que aliás foi criado - são expoentes dessas vertentes Lipset (1997) e Sombart (1976) e, para uma discussão teórica dessas vertentes e seu impacto na teoria política, cf. Fagundes (2008).
} 
se realiza mediante a efetividade das liberdades. Isso tem implicações importantes, entre elas a ideia de que pode haver um continuum de efetivação democrática, ainda sob a dimensão única da efetividade das liberdades, e, consequentemente, democracias diferentes. Umaleituramais extrema poderia identificar democracias típicas, qualitativamente diferentes, desdobrando em elementos plurais as características de efetividade das liberdades. Assim, pioneiro em perceber uma trajetória ineludível de democratização nas sociedades modernas, Tocqueville também destacou características modulares da efetivação da democracia: seguindo Montesquieu, considerou que as instituições, mesmo singulares, não operam no vazio, são moduladas pelo que houve antes, por pressões do presente e ambições finalistas. As democracias estão, portanto, em permanente transação de tempos históricos, sendo estruturalmente afetadas pela experiência, institucional e cívica, do que veio antes e do que está determinado a vir.

A interpretação histórica de Tocqueville se volta a um caso, específico, em que se busca manter a liberdade em uma sociedade que não teve aristocracia, a sociedade norte-americana. Não se trata de negar ou sobrevalorizar uma trajetória histórica, mas de indicar seu fundamento e, em tom pessoal do autor, louvar seus méritos. Elemento-chave na dinâmica de constituição dessa sociedade específica é seu movimento de negação positivo do passado, ou seja, negação em prol da afirmação e reconstituição da pessoa, num retorno às Sagradas Escrituras em detrimento da tradição mais imediata (VOUGA, 2002, p.252).

O movimento de negação positivo do passado - em que positivo não é usado em acepção valorativa, mas na acepção de ato com vista em um fim estabelece um parâmetro de compreensão da ação política. Para Tocqueville, os cidadãos devem lutar pelos ideais liberais e as revoluções, em condições determinadas, são necessárias, por exemplo, nas nações cujos cidadãos não são capazes de conduzir o processo democrático com liberdade. A democracia não é apenas igualitária, mas deve também permitir homens livres.

A linha teórica tocquevilleana se fundamenta em um ambicioso repensar da Teoria da História. Faz-se em oposição a uma perspectiva aplainadora da realidade historicamente apreendida, qual seja, a redução da diversidade dos fenômenos a uma unidade artificial determinista:

[O] perigo [do determinismo], nada negligenciável, é a história que se transforma em uma espécie de cabo ou corda, em uma imensa correia de transmissão estendida no tempo, em que os acontecimentos se ligam uns aos outros como que automaticamente, 
impelidos por uma força ou potência (destino) a conduzir as mãos dos homens como se fossem marionetes - que dizer, uma história sem acontecimentos, sem ações e sem homens (DOMINGUES, 1996, p.100).

Não há, entretanto, em A democracia na América um telos historicamente determinado. Tocqueville "aposta" na existência provável de um futuro, mas não o prediz: a democracia é vista como uma era, um tempo no qual os povos chegam por haver um Deus que os percebe como iguais. Dessa forma, a igualdade se transforma em uma tendência histórica. É no seio dessa linha histórica, ainda que apenas tracejada, que Tocqueville introduz a experiência dos Estados Unidos como um meio termo entre a experiência inglesa e a francesa. Trata-se de um país de posição intermediária, uma vez que, ao contrário da França, já existe, originariamente, uma experiência de democracia:

[...] os norte-americanos constituem um povo democrático que sempre dirigiu por si mesmo os negócios públicos, e [os franceses] somos um povo democrático que, durante muito tempo, só pôde pensar em uma melhor maneira de conduzi-los. A nossa situação social já nos levava a conceber ideias bastantes gerais em matéria de governo, enquanto a nossa constituição política ainda nos impedia de retificar tais ideias pela experiência e de descobrir pouco a pouco a sua insuficiência, ao passo que, entre os norteamericanos, essas duas coisas se equilibram constantemente e se corrigem mutuamente (TOCQUEVILLE, 1977, p.331).

A dinâmica temporal em Tocqueville é singular, vale notar. Para Domingues (1996, p.129), “[...] pode algo que foi e não é mais (o passado) agir sobre algo que não é e não será mais (o presente), assim como sobre algo que será e não é ainda (o futuro)?”. A interpretação dos acontecimentos e estruturas históricas que permeiam a análise da obra tocquevilleana busca identificar parâmetros para conectar o tempo histórico em transação, entre esses elementos do ser-que-passou, do estar-a-ser e do vir-a-ser. Outra interpretação de Domingues (1996, p.148) é esclarecedora sobre a dinâmica dos tempos na construção da teoria do tempo histórico de Tocqueville, introduzindo "o seguinte esquema para pensar a relação entre o passado o presente e o futuro: passado necessário (pois os acontecimentos ocorridos no passado, uma vez ocorridos, não podem ser revertidos, mesmo que em sua origem esteja algo contingente) / presente (in)definido (em parte 
determinado pelo passado, em parte voltado para o futuro, em parte dobrado sobre si mesmo, enquanto tempo da (re)atualização, da criação e da urgência da ação) / futuro aberto (determinado pelo passado, porém criado no e pelo presente, que é a instância propriamente geradora da temporalidade)". Para Tocqueville, assim, “o tempo não pode ser reposto a não ser pelo próprio tempo; assim, experimentando novas formas de convívio, os homens 'treinariam' a democracia naturalmente para que ela ganhasse raízes” (FAGUNDES, 2008, p.140). A chave explicativa dessa transação se coloca no campo da ação humana livre - que condiciona o tempo histórico que o determina -, enquanto experiência inovadora e prospectiva. Isso porque a introdução de um princípio de indeterminação do ser leva ao enfraquecimento da necessidade e à assunção da contingência, bem como à incorporação da mudança e do novo.

\section{Filosofia prática e religião}

A viagem que Tocqueville fez aos EUA, à época da restauração do regime monárquico na França, após a queda de Napoleão, e seu contato com a forma cívica das comunas da Nova Inglaterra possibilitaram-lhe entrar em contato com uma realidade descolada da tradição política aristocrática europeia e marcada por singularidades e idiossincrasias e repensar a sua própria experiência cívica e a França de seu tempo a partir de um novo parâmetro: a concepção norte-americana de Estado e democracia. Ele analisou um estilo democrático e um modo de engajamento cívico que lhe pareciam absolutamente novos. Vale notar que a pluralidade de experiências vivenciadas ao longo de sua viagem - a incipiente urbanidade em Nova York, a escravidão no Sul, a wilderness às margens dos Grandes Lagos - ensejou um quadro descritivo plural, considerando a multiplicidade de configurações sociais que compunham o cenário norte-americano, mas, indo além dos particularismos, vislumbrou um caso histórico singular e radical (JASMIN, 2001).

A experiência democrática norte-americana, segundo Tocqueville, se caracteriza por uma espécie de Estado Social. Compreende, portanto, democracia como um tipo de sociedade, não como uma forma de governo, mantendo-se nessa linha tributária de Montesquieu. O "patriotismo municipal" das comunas e a "liberdade política local" são a energia criadora que anima os indivíduos a tomarem para si a resolução conjunta de seus problemas coletivos, cuja origem remonta às próprias práticas cotidianas 
da cidadania. Tocqueville percebeu que, em contraposição à França de seu tempo, onde os interesses das diversas facções pareciam impossibilitar uma ordem democrática, nos Estados Unidos, “[...] os costumes respiravam uma espécie de virtude que, sem anular os interesses particulares, os fazia servir às instituições livres", na análise de Jasmin (2002, p.71). Chama a atenção do pensador francês o modo específico de organização social norte-americana:

Os homens que vivem em sociedade não seriam mais capazes de buscar as suas crenças nas opiniões de classe à qual pertencem, pois, por assim dizer, não mais existem classes, e as que existem ainda são compostas de elementos tão móveis que o corpo jamais poderia exercer ali um verdadeiro poder sobre os seus membros (TOCQUEVILLE, 1977, p.322).

Na sociedade norte-americana, a combinação entre satisfações individuais e envolvimento com o negócio público se dá de maneira diferente do que existe no Velho Continente, segundo Tocqueville. "Antes de mais nada, será preciso qualificar o adjetivo público, [...] Tocqueville nos mostra sua abrangência e em que ele consiste. Trata-se dos hommes de lettres que, no contexto da Revolução Francesa, ocuparam a cena pública e engajaram-se na política, aliando a pena e a baioneta" (DOMINGUES, 2011, p.470). A resposta analítica à possibilidade de combinação e coesão da comunidade se apresenta, pelo menos parcialmente, na identificação de um traço peculiar da filosofia norte-americana, vista como eminentemente prática. Compreendida em sua concretude pelos próprios norte-americanos, povo tido por Tocqueville como eminentemente ignorante das letras e da tradição filosófica, a filosofia prática, desprovida de maiores reflexões metafísicas ou especulativas, orienta as práticas cotidianas, fazendo com que os americanos "vivam filosoficamente". Trata-se, pois, de uma filosofia empírica e eminentemente individualista. Cada indivíduo, desconsiderando a tradição erudita, reinventa seu próprio mundo: "cada norte-americano só apela para o esforço individual da sua razão. Por isso é a América um dos países do mundo onde se estuda menos e onde se segue os preceitos de Descartes" (TOCQUEVILLE, 1977, p.321). Uma das características da "vida filosófica" norte-americana é uma homogeneização das qualidades, com uma volta à própria razão e sua apreensão como a única detentora da verdade e das faculdades de se julgar o mundo.

A vida política peculiar nos Estados Unidos está intimamente vinculada a uma formação social que a estrutura. A "vida filosófica" só é possível na 
medida em que se estabelecem condições de base para seu desabrochar, sua normalização. O igualitarismo norte-americano, fundante da democracia, se estabelece a partir da estruturação das condições mínimas para sua preservação e continuidade. "[A] força do igualitarismo era tão penetrante em todos os domínios da vida social norte-americana, que via sérios riscos para a manutenção futura dos direitos individuais, da liberdade de expressão e da pluralidade de pensamento" (BEIRED, 2003, p.64). Não há administração da vida pública como há na França, mas a genealogia da formação social norte-americana, que Tocqueville realiza, indica a presença de algum tipo, próprio, potencializador e garantidor da democracia, que encontra alicerce ideário na tradição bíblica e na filosofia secular.

Nessa genealogia da sociedade norte-americana, Tocqueville constata que foi especialmente no século XVIII que os "homens das letras" começaram a se envolver em política. Tanto a revolução americana quanto a francesa tiveram seus princípios norteados pelos ideais do Iluminismo, mas foi nas terras da Nova Inglaterra que tais princípios foram efetivamente mais bem colocados em prática. Essa "sofisticação" da política permitiu que os EUA das primeiras décadas do século XIX fossem capazes de articular um sistema de organização baseado em uma nova compreensão de Constituição, entrelaçada em sua configuração com o Estado Social, que aniquila a necessidade histórica de revoluções democráticas. Foi através da promulgação de uma Constituição "institucionalmente ingênua" que permitiu o reconhecimento positivo dos homens, em que, em vez de buscar a reforma da natureza humana, como foi a tradição europeia, se deu a conexão entre interesses e paixões individuais e a vida equilibrada em sociedade (TESSITORE, 2002). A aceitação do homem como ele é, sinalizada aliás nos pronunciamentos dos legisladores norte-americanos, que depositam pouca confiança na honestidade de seus concidadãos, preferindo, orienta filosoficamente a construção das estruturas da vida social.

$\mathrm{Na}$ análise genealógica da religião, afere-se que, "nos Estados Unidos, a religião confunde-se, pois, com todos os hábitos nacionais e todos os sentimentos que a pátria faz nascer; isso lhe dá uma força particular" (TOCQUEVILLE, 1977, p.323). É importante lembrar que Tocqueville se voltou, sobretudo, para a realidade dos Estados que constituíam a colônia da Nova Inglaterra, cuja criação se deveu, em grande parte, a fatores eminentemente religiosos.

A trajetória religiosa norte-americana se deve à evolução de duas características da filosofia da Ilustração, evolução que se diferenciou do que 
ocorreu na Europa. A primeira consistia em considerar a natureza humana a partir de um cogito autônomo e isolado; a segunda era, justamente, o caráter antirreligioso (TESSITORE, 2002). Mas o próprio Tocqueville percebeu que esses dois princípios constitutivos da filosofia política iluminista não foram da mesma forma recepcionados na América do Norte. É inegável que os pensadores iluministas influenciaram, profundamente, os esforços das colônias da Nova Inglaterra em se identificarem enquanto nação; porém, a carga antirreligiosa, tão presente no pensamento europeu, não se espraiou em terras americanas.

A migração dos puritanos foi um movimento religioso fundamentado em uma crença primitiva na Bíblia. É justamente devido a essa dimensão do puritanismo que os habitantes da Nova Inglaterra puderam incorporar as teorias democrática e republicana (TESSITORE, 2002). Isso possibilitou, na formação dos Estados Unidos, o surgimento de um conjunto de leis e normas que parecia antecipar, ainda que de maneira inexata, o espírito de liberdade dos tempos de sua viagem, em contraste com um código penal invasivo aplicado alhures.

A cultura anglo-americana se consolidou a partir da junção de dois fatores que, ao longo da tradição europeia, foram recorrentemente vistos como opostos: o espírito religioso e o espírito de liberdade. Trata-se de uma inovação do ponto de vista da formação societal, que se originou das perseguições religiosas na Europa e se substancializou a partir da dinâmica comunitária própria ao Novo Mundo nascente; as perseguições religiosas alimentaram o fervor religioso dos fundadores pioneiros que, nos Estados Unidos, se viram livres para agir segundo suas convicções mais profundas, o que Tocqueville identificou como "o estado natural do homem em questão de religião".

Nessa narrativa falta, entretanto, um elo entre o "método filosófico dos americanos" e a "formação religiosa" do povo. A descoberta de Tocqueville é importante, pois revela uma religião que se estrutura autonomamente, fixando seus próprios limites. Trata-se de uma realidade nova, uma configuração religiosa que se distinguiu quase inteiramente da ordem política, apartada:

[...] de tal sorte que se puderam modificar facilmente as leis antigas sem abalar as antigas crenças. Assim, conservou o cristianismo grande domínio sobre o espírito dos norte-americanos e, fato que desejo assinalar particularmente de modo nenhum reina apenas como uma filosofia que se adota depois de um exame, mas como uma religião na qual se crê sem discutir (TOCQUEVILLE, 1977, p.323). 
Assim, os norte-americanos assumiram para o âmbito pessoal as verdades morais, e é desse entrelaçamento entre moral e religião, autonomia do indivíduo e coesão do grupo, que se inscreve o aporte analítico de Tocqueville. $\mathrm{Na}$ verdade, ele não apresenta em detalhe os mecanismos de que se vale a religião para influenciar a sociedade norte-americana, mas se desprende de suas observações a importância desse aspecto.

Um dos aspectos próprios dessa comunidade político-religiosa analisada por Tocqueville, que resulta da "associação" entre Lutero (com seu livre exame de consciência), Descartes e Voltaire, é a recusa radical do ritualismo. Essa recusa é às vezes vista como "simplicidade", mas o termo - dúbio pode ser enganoso. De fato, há simplicidade no sentido de haver menos complexidade no exercício político e religioso, tornando ambos mais diretos e individualizados, sem mediações complicadas. Mas não há simplicidade se esta for entendida como humildade, uma aversão à forma pela valorização da substância e uma incredulidade no sobrenatural, na crença, na ideia da existência de uma razão humana elevada, combinada com uma difícil identificação ou submissão a uma autoridade intelectual superior e para além da humanidade.

Vale notar que Tocqueville não desconsiderava a possibilidade de distanciamento do homem da religião, mas afirmava que essa negação das próprias crenças era, na verdade, uma espécie de "aberração intelectual" que forçava o indivíduo a violar sua própria condição natural de homem (TESSITORE, 2002). Para o autor, a separação entre religião e política não era apenas benéfica para a política, mas, especialmente, para a religião, uma vez que isso permitia que o sentimento religioso fosse percebido e aflorasse por aquilo que o fundamentava de maneira legítima: o princípio constitutivo da natureza humana.

\section{Individualismo democrático}

Em sua análise, Tocqueville apresenta um aparente paradoxo para a constituição da sociedade norte-americana: a constituição de uma sociedade democrática sobre bases aparentemente particulares e exclusivistas. Porém, é essa configuração que permite que os homens, em situação de igualdade, possam, pela similaridade que os identifica, especular, julgar e pressupor que todos possuem conhecimentos parecidos, o que, consequentemente, leva-os a validar o princípio de verdade segundo o qual a verdade encontra-se do 
lado da maioria deles.

É mister pensar aqui, tendo em vista o processo igualitarista, os perigos da ditadura da maioria e a consequente perda da liberdade, numa perspectiva milliana. Há pelo menos dois riscos. "[O] despotismo das massas a que Tocqueville chama de tirania da maioria são formas próprias do mundo moderno que, ao destruir a essência básica do espírito aristocrático, ameaçam a liberdade do cidadão e projetam sombras imprevisíveis sobre o futuro" (MAGALHÃES, 2000, p.150). Primeiro, há a perspectiva de a maioria destruir as possibilidades de manifestação de minorias ou de indivíduos diferenciados e isolados, o que representaria, em suma, um movimento propriamente contrário ao individualismo. Um segundo risco é o advento de um Estado autoritário despótico, em que o Estado concentra todas as atividades, limitando as liberdades fundamentais.

Ao contrário de Mill, para Tocqueville a opinião da maioria exerce um papel moderador dos juízos individuais. No interior do Estado Social, à opinião da maioria caberia apenas tudo o que é igual, sem prejuízos para a descentralização naquilo que houvesse de diferente. Dessa forma, quando há descentralização administrativa há uma multiplicação do poder e da autoridade no interior da sociedade em virtude de uma participação "forçada" dos indivíduos na política. Para Tocqueville, a própria atividade política dos cidadãos pode impedir que os perigos millianos ocorram. Ele considera que a existência e a manutenção de certas instituições podem dificultar o surgimento de um Estado autoritário e de uma sociedade massificada. Tocqueville não se debruça diretamente sobre o Estado, pois o que procura analisar é a díade livre exame e opinião da maioria. Essa preocupação se deve ao fato de não ser possível aos homens tematizarem, a todo momento, todas as questões do mundo da vida. Ao contrário de Deus, que pensa o gênero humano em sua individualidade, ao espírito humano é defeso agir dessa maneira - diz Tocqueville -, sob pena de perder-se na imensidão de detalhes típica da pluralidade de sua sociedade. Restam aos homens, portanto, reconhecer a insuficiência de sua inteligência e criar artifícios - ideias gerais - com os quais possam se orientar:

As ideias gerais têm a qualidade admirável de permitirem ao espírito humano fazer juízos rápidos sobre grande número e objetos de uma vez; mas, por outro lado, nunca lhes fornecem senão noções incompletas, e sempre lhe fazem perder em exatidão o que dão em extensão (TOCQUEVILLE, 1977, p.328). 
É a identificação religiosa dos homens enquanto semelhantes entre si que os aproxima tanto em perspectiva cristã quanto democrática. A partir da associação entre ideias gerais e divina providência, herança da tradição religiosa, o princípio da igualdade assume a posição de regra geral. Assim, Tocqueville aponta no mundo burguês algo que remonta à tradição aristocrática: "a qualidade de saber manter unidos os desiguais, transferida agora para o mundo de homens iguais nas suas condições, mas desprovidos de elos que os unam" (COHN, 2000a, p.33). A percepção de que os homens são semelhantes entre si, associada à tradição cristã da existência de um Deus único que trata todos os homens igualmente, ou seja, um monoteísmo vinculado a ideias gerais, possibilita um desdobramento analítico importante, o argumento que associa Deus e ideias gerais pela via do cristianismo:

Homens semelhantes e iguais concebem facilmente a noção de um Deus único, que impõe a cada um deles as mesmas regras e lhes concede a felicidade futura pelo mesmo preço. A ideia da unidade do gênero humano leva-os sem cessar à ideia da unidade do Criador, ao passo que, ao contrário, homens muito separados uns dos outros e muito dessemelhantes chegam de bom grado a constituir tão numerosas divindades quantos são os povos, as castas, as classes e as famílias, e a traçar mil caminhos particulares para ir ao céu (TOCQUEVILLE, 1977, p.334).

Assim, passa a haver uma certa regulação da relação cristianismodemocracia pela religião, cujas características já foram anteriormente explicitadas.

A interseção entre religião e política provoca modificações na prática religiosa. A religião nos Estados Unidos tem um papel de mediação entre o divino e o terreno diminuído, passando a apresentar uma relação com o mundo. Aqui, o sobrenatural não é o objetivo último a ser alcançado; há uma revalorização das relações com o cotidiano e com a salvação da vida. Esse entendimento da religião solidifica a concepção de democracia norte-americana, já que se trata de uma quase-interpretação cosmológica (panteísta) da cristandade. Isso pelo fato de, no panteísmo, graças a uma radicalização do tomismo, haver uma naturalização de Deus e a percepção do mundo como uma só categoria. A figura de Deus distancia-se da visão agostiniana, segundo a qual o mundo das ideias está sujeito a alterações oriundas de desígnios divinos.

Para Tocqueville (1979), a democracia deve ser entendida como uma dimensão da Providência que, por ser diferente da fatalidade, faz parte 
do mundo da experiência e, consequentemente, implica vários caminhos possíveis. Dessa forma, é possível traduzir - tradução que implica, necessariamente, tradição - a ciência pura, típica dos países de história aristocrática, em preceitos de uma ciência prática. A partir da relação entre democracia, liberdade e igualdade, Tocqueville acaba por apreender esta última como uma paixão mais arraigada que a liberdade. Isso estabelece um princípio de ordenamento de valor que, pela tradição totalitária, pode ser entendido como a aceitação de que os homens pensam em si mesmos enquanto iguais perante a lei ou, pela formação cristã, pode remeter à ideia de que a liberdade foi compreendida tradicionalmente como o poder de agir segundo o próprio arbítrio, e não como capacidade de participar da política. Aceitando-se a hipótese de que a sociedade é movida segundo a paixão (a igualdade), surge uma nova disposição nos homens: o individualismo, cuja consequência primeva é o isolamento em relação ao corpo social, passando cada qual a viver como se fosse, em si mesmo, toda uma sociedade.

Pela chave da "redescoberta" da liberdade, Tocqueville apresenta uma progressão desse individualismo:

Os norte-americanos combatem, por meio da liberdade, o individualismo que a igualdade fazia nascer, e o venceram. Os legisladores da América não acreditaram que, para curar uma enfermidade tão natural ao corpo social nos tempos democráticos, e tão funesta, bastava conceber à nação inteira uma representação de si mesma; pensaram que, a demais disso, seria conveniente dar uma vida política a cada porção do território, a fim de multiplicar ao infinito, para os cidadãos, as ocasiões de agir em conjunto e de fazê-los sentir todos os dias que dependem uns dos outros (TOCQUEVILLE, 1977, p.389).

A associação da ideia de uma sociedade igualitária (na qual o princípio político migraria da aristocracia para o conjunto dos indivíduos iguais) com a liberdade política (que pressupõe uma certa igualdade distributiva) acaba por gerar o risco de o "poder de todos" confundir-se com o "poder de ninguém”, além daquele risco de a dádiva da participação igualitária mostrar-se na forma de uma alienação cívica. Com isso, toma forma a imagem do despotismo democrático, cuja aparência de liberdade mascara a transfiguração dos indivíduos autônomos em seres incapazes de exercer plenamente suas faculdades humanas (JASMIN, 2002), uma vez que, se cada indivíduo cuidar apenas de seus interesses particulares, o interesse público 
ficará à mercê do "déspota”. Tocqueville salienta que a ideia da defesa do interesse público acaba sendo boa para cada indivíduo singular. Mas essa perspectiva pressupõe indivíduos prontos para "construir a política".

$\mathrm{O}$ fato de os norte-americanos se autogovernarem e trazerem suas ideias para o nível da experiência significa que há também neles algo de aristocrático. Afinal, na tradição política norte-americana, o poder descentralizado das comunidades em deliberar sobre questões que não são de domínio geral faz com que a ideia de poder perpasse toda a sociedade. As divisões que eram "naturais" na aristocracia (senhores que controlavam seus territórios) são transpostas para a comunidade, que passa a operar como "senhores" em determinadas esferas da vida. Esse misto de princípio aristocrático e democracia é visto por Tocqueville como a alternativa ao totalitarismo de um Estado central, aquele que comandaria um povo massificado, preocupado apenas com suas atividades particulares.

A realização dos atributos humanos depende de contínua autonomia e responsabilidade/responsabilização moral e política, o que o cristianismo alicerça. Mas Tocqueville percebeu uma falha na moral cristã, que o levou a salientar a necessidade do agir político:

Os deveres dos homens entre si enquanto cidadãos, as obrigações públicas, me parecem mal definidas e bastante negligenciadas na moral do cristianismo. Eis aí, me parece, o lado frágil desta admirável moral, e que é o único lado verdadeiramente forte da moral antiga (TOCQUEVILLE apud JASMIN, 2002, p.75).

$\mathrm{Na}$ perspectiva tocquevilleana, é importante que os indivíduos sejam dotados de uma virtude cívica, que lhes garanta confiança de suas capacidades frente ao Estado, à sociedade e à história, e que seja fundamentada em uma educação política prática que sustente essa confiança. Os indivíduos, empoderados, estabelecem uma rede de limite à expansividade do Estado burocrático, tendência normal em outro contexto na visão de Tocqueville, e garantem, a partir de posições de interesses diversos, a elaboração de metas coletivas e participam diretamente da administração da coisa pública. É essa soberania, exercida na comunidade local, que permite aos indivíduos pensarem a si próprios como comandantes de seus destinos, fazendo-os agir segundo seu livre-arbítrio.

No contexto do individualismo moderno, a "necessidade" da política se torna salvação, na medida em que a atividade pública destina-se a romper o círculo vicioso de ligação entre individualismo, particularismo e despotismo. 
A base para a liberdade política se vê, portanto, indiscutivelmente associada ao espírito de cidadania, fazendo com que a política não mais seja vista como uma competição agonística entre indivíduos apenas preocupados em satisfazer seus interesses pessoais. Vale notar que, para Tocqueville, tanto o "fazer o bem sem interesse" quanto as doutrinas morais do desprendimento perderam forças ao longo da história (JASMIN, 2002), e a experiência norteamericana, que não é exclusiva em seu tipo de engajamento cívico, mas é um estágio superior, com a identificação racional entre interesses particulares e os da cidadania, pode se difundir e reverter o quadro de isolamento imposto pelo princípio de privacidade individualista. "[Tocqueville] atribui ao engajamento do cidadão em nível local valor fundamental não apenas para a democracia local em si, mas também para dar sustentação à democracia no nível nacional" (FREY, 2000, p.90).

A participação comunal, juntamente com as liberdades locais, impede o quadro desolador do individualismo, tal qual surge nos Estados Unidos. Isso se deve, segundo Tocqueville, à doutrina do interesse bem compreendido, bastante difundida entre os norte-americanos:

A doutrina do interesse bem compreendido não é nova, portanto. Mas, entre os norte-americanos de hoje, foi universalmente admitida; tornou-se popular: encontramo-la no fundo de todas as ações; ela penetra através de todos os discursos. Não a encontramos menos na boca do pobre que na do rico (TOCQUEVILLE, 1977, p.401).

Tocqueville faz aqui uma releitura inovadora da teoria republicana de Montesquieu, ao resgatar o antigo princípio da virtude:

Os norte-americanos não formam um povo virtuoso e no entanto são livres. O que não prova de modo algum que a virtude, como pensava Montesquieu, não seja essencial à existência das repúblicas. Não se deve tomar a ideia de Montesquieu em sentido estreito. O que o grande homem quis dizer é que as repúblicas só podiam subsistir pela ação da sociedade sobre si mesma. O que ele compreende como virtude é o poder moral que cada indivíduo exerce sobre si mesmo e que o impede de violar o direito dos outros. [...] Na América não é o desapego aos interesses que é grande, é o interesse que é bem compreendido, o que também dá quase no mesmo. Montesquieu tinha então razão quando falava da virtude antiga e o que diz dos gregos e dos romanos também se aplica aos americanos (NOLLA apud JASMIN, 2002, p.79-80). 
"Discípulo de Montesquieu, Tocqueville, como o barão de la Brède, sabe perfeitamente que modelos institucionais não atuam no vazio, independentemente de meio físico, clima, costumes etc." (VOUGA, 2001, p.120). Jasmin afirma que as experiências nas comunas, a existência de uma vida cívica "viril" e um grande número de cidadãos que participam diretamente dos processos de deliberação política e da própria administração não implicam a existência de uma comunidade de virtuosos, na existência de homens "imbuídos do dever de participação como antídoto consciente do despotismo" (JASMIN, 2001, p.208). Mesmo porque, no mundo, tal qual descrito por Tocqueville, a democracia goza da participação de poucos homens virtuosos, com um tipo escasso de convicção religiosa.

\section{Conclusão}

Tocqueville percebeu algo de novo no cenário anglo-americano que permitia surgir, numa comunidade formada por não virtuosos, resultados virtuosos. Tratava-se de um mecanismo que produz participação pública, apesar da tradição de valorização da privacidade e do autointeresse. Tratava-se, pois, do equivalente moderno da virtude dos antigos:

O conceito mobilizado por Tocqueville, nessa direção, é o do "interesse bem compreendido" que justamente descreve os modos pelos quais os indivíduos identificam a sua presença na discussão e na gestão da coisa pública como porte integrante do seu autointeresse (JASMIN, 2001, p.209).

Mas o interesse bem compreendido é uma doutrina moralmente fraca, apesar de resultar de duas características enraizadas no interior da sociedade norte-americana: a existência de um egoísmo que faz com que cada um apenas pense em si próprio e a concentração da alma nas coisas materiais (JASMIN, 2002). O interesse bem compreendido, se não forma indivíduos virtuosos, resulta, ao menos, em indivíduos mais comedidos e impede os homens de se perceberem para além do nível ordinário da sociedade:

O interesse bem compreendido é uma doutrina pouco elevada, mas clara e segura. Não tem em vista atingir grandes objetivos, mas atinge sem demasiados esforços todos aqueles que tem em vista. Como está ao alcance de todas as inteligências, cada um a toma facilmente e a conserva sem dificuldades (TOCQUEVILLE, 1977, p.402). 
O autogoverno não é para Tocqueville um mero dispositivo constitucional, mas a própria forma política da liberdade, sua estrutura. É através dele que, além de serem constituídas as formas institucionais livres, os homens realizam a própria aprendizagem da liberdade. Assim, como nota Cohn (2000b), Tocqueville, crítico do Iluminismo, maximiza o ideal iluminista de emancipação e liberdade. A democracia é, nessa linha, fundamentada na constituição de homens independentes, autônomos frente a um poder externo, mas vinculados a partir de uma interdependência entre iguais, cívica.

A democracia tocquevilleana é um "modo de ser" da sociedade, como uma condição social de igualdade de condições, sob as quais vivem os homens, que não precisa passar por sua vontade consciente (COHN, 2000b). Essa situação se estrutura a partir de parâmetros societais identificáveis, não nascendo a esmo a partir de predisposições individuais. As condições da democracia, aqui argumentamos, são culturais e institucionais, e estão no cerne da teoria da religião e da política em Tocqueville.

\section{Referências}

BEIRED, José Luis Bendicho.

(2003). Tocqueville, Sarmiento e Alberdi: três visões sobre a democracia nas Américas. História, v. 11, n. 2, p. 59-78.

COHN, Gabriel.

(2000a). Perfis em Teoria Social: Tocqueville e Weber, duas vocações. In: AVRITZER, L.; DOMINGOS, J. M. Teoria social e modernidade no Brasil. Belo Horizonte: Ed. UFMG, p. 27-37.

COHN, Gabriel.

(2000b). Tocqueville y la pasión bien comprendida. In: Atílio Boron; La Filosofia Política Moderna: de Hobbes a Marx. Buenos Aires: CLACS0, p. 247-267.

DOMINGUES, Ivan.

(2011). 0 intelectual público, a ética republicano e a fratura do éthos da ciência. Scientiae Studia, v. 9, n. 3, p. 463-485.
DOMINGUES, Ivan.

(1996). O Fio e a Trama: reflexões sobre o tempo e a história. São Paulo: Iluminuras; Belo Horizonte: Ed. UFMG.

FAGUNDES, Bruno Flávio Lontra.

(2008). Matrizes do pensamento culturalista: Tocqueville e Almond-Verba. Lua Nova, n. 74, p. 131-150.

FREY, Klaus.

(2000). Descentralização e poder local em Alexis de Tocqueville. Revista de Sociologia e Política, n. 15, nov., p. 83-96.

GAHYVA, Helga.

(2012). De Boulainvilliers a Tocqueville: da liberdade como defesa de privilégios à liberdade como defesa de diferenças. Sociologias, ano 14, n. 31, p. 168-190.

GOLDBERG, Chad Alan.

(2001). Social citizenship and a reconstructed Tocqueville. American Sociological Review, v. 66, n. 2, p. 289-315. 
JASMIN, Marcelo Gantus.

(2002). Interesse Bem Compreendido e Virtude em A Democracia na América. In: Newton Bignotto; Pensar a República. Belo Horizonte: Ed. UFMG, p. 71-85.

JASMIN, Marcelo Gantus.

(2001). As Américas de Tocqueville: a comunidade e o auto-interesse. In: SOUZA, Jessé. Democracia hoje: novos desafios para a teoria democrática contemporânea. Brasília: Ed. Unb, p. 201-211.

LIPSET, Seymour Martin.

(1997). American Exceptionalism: a Doubleedged sword. WW Norton \& Company.

MAGALHÃES, Fernando

(2009) Tocqueville e a perspectiva da democracia individualista. Tempo Social, v. 12, n. 1, p. 141-164.

SANTOS, Rosmália Ferreira.

(2004). Individualismo romântico e modernidade democrática: uma configuração mútua. Revista de Sociologia e Política, n. 23, nov., p. 89-101.

SKOCPOL, Theda.

(1997). The Tocqueville problem: civic engagement in American democracy. Social Science History, v. 21, n. 4, p. 455-479.

SOMBART, Werner.

(1976). Why is there no socialism in the United States?. ME Sharpe.

TESSITORE, Aristide.

(2002). Alexis de Tocqueville on the Natural State of Religion in the Age of Democracy. The Journal of Politics, v. 64, n.4, nov., p. 11371152.
TOCQUEVILLE, Alexis de.

(1977). A Democracia na América. Belo Horizonte: Itatiaia; São Paulo: EdUSP.

TOCQUEVILLE, Alexis de.

(1979). O Antigo Regime e a Revolução. Brasília: Ed. Unb.

VIANNA, Luiz Werneck.

(1997). 0 problema do americanismo em Tocqueville. In: A revolução passiva: Iberismo e americanismo no Brasil. Rio de Janeiro: Revan, p. 89-124.

VOUGA, Cláudio.

(2002). La democracia em el Sur América, uma visión tocquevilleana. In: Alvaro de Vita; Atílio Boron; Teoría y Filosofía Política: la recuperación de los clásicos en el debate latinoamericano. Buenos Aires: CLACSO, p. 247-258.

VOUGA, Cláudio.

(2001). A democracia ao sul da América: uma visão tocquevilleana. Tempo Social, v. 13, n. 1, p. 117-128.

WHITE, Hayden.

(1994). Trópicos do Discurso: ensaios sobre a crítica da cultura. São Paulo: EdUsp.

\section{Recebido em}

novembro de 2013

Aprovado em

janeiro de 2014 